\title{
Facilities Management Carbon Footprints: An Audit of Critical Elements of Management and Reporting
}

\author{
Abbas Elmualim and Wisdom Kwawu \\ School of Construction Management and Engineering, University of Reading, Reading RG6 6AW, UK
}

\begin{abstract}
Concern for the environmental impact of organizations' activities has led to the recognition and demand for organizations to manage and report on their carbon footprint. However, there is no limit as to the areas of carbon footprints required in such annual environmental reports. To deliver improvements in the quality of carbon footprint management and reporting, there is a need to identify the main elements of carbon footprint strategy that can be endorsed, supported and encouraged by facility managers. The study investigates carbon footprint elements managed and reported upon by facility manager in the UK. Drawing on a questionnaire survey of 256 facility managers in the UK, the key elements of carbon footprints identified in carbon footprint reports are examined. The findings indicate that the main elements are building energy consumption, waste disposal and water consumption. Business travel in terms of using public transport, air travel and company cars are also recognized as important targets and objectives for the carbon footprint strategy of several FM (facilities management) organizations.
\end{abstract}

Key words: Facilities management, sustainability policy, carbon footprint and environmental impact.

\section{Introduction}

Following the implementation of the Climate Change Act in 2008 [1] the UK government has committed to reducing the UK's carbon emission targets to $34 \%$ by 2020 , and $80 \%$ by 2050 , based on 1990 levels. Although the act is meant to move the UK towards a low-carbon economy by improving sustainable development and carbon management, like many other countries, it faces many challenges in meeting its carbon reduction target. These challenges include dealing with the built environment which accounts for nearly $40 \%$ of limited natural resources consumed, and $40 \%$ of waste and GHG (greenhouse gas) generated [2].

The UK government is using regulatory and legislative requirements to encourage businesses to reduce or manage their GHG emissions, through efficient management of energy and waste [3, 4]. As a consequence, businesses in the UK are increasingly

Corresponding author: Abbas Elmualim, $\mathrm{PhD}$, senior lecturer, research field: sustainable built environments. E-mail: a.a.elmualim@reading.ac.uk. incorporating within annual reporting mechanisms, their strategies for mitigating their GHG emissions, as part of their environmental responsibilities [4, 5]. Hence, besides bottom line financial results, the reports now contain statements about environmental impacts and responsibilities.

Within businesses, compliance with these requirements and abatement action is often the responsibility of facilities managers [6, 7]. A major concern for facilities managers, however, is that there appears to be no uniformity in the key issues that need to be addressed in the annual environmental impact reports and actual practice [8]. There is no consensus on the issues that need close monitoring in carbon footprint management strategies. A good starting point is to audit carbon footprint strategies that are reported in organizations' annual reports.

The environmental reports, often, seek to establish sustainable frameworks for integrating sustainability concerns into core business strategies [4, 7] and stimulate good carbon management practices within the organization. Professional facilities management activities have a significant influence over how 
facilities are used and therefore tasked to manage and report on carbon footprints. Thus facilities managers are at the forefront of implementing their organization's vision and commitment towards carbon footprint management strategies. Carbon management may mean different things to different organizations, however the lack of general agreement on the key elements to report on suggest a growing need to identify key elements addressed in annual environmental responsibility reports and make it more uniform.

This paper examines the common critical issues addressed in carbon footprint reports, through a literature review and a questionnaire survey of the facilities managers. Identification and prioritization of key issues will lead to improvement or development of good sustainable practices for carbon footprints management and reporting. In addition, key elements addressed in environmental impact and responsibility reports reveal how facilities managers are engaging with reducing carbon emissions.

\section{Importance of Carbon Footprints}

It is now widely recognized that GHG emissions are producing measurable climate change and there is an urgent need to reduce the production and effect of GHG $[1,9]$. Of the GHG generated, $85 \%$ are carbon dioxide, produced from burning fossil fuels for electricity, building heating, manufacturing and transportation. It is the most significant contributor to climate change and much of it is due to population and economic growth in both the developing world, mainly China and India, and the developed world $[10,11]$. The IPCC (Intergovernmental Panel on Climate Change) report [10] concluded that global warming and climate change was "unequivocal", and the main driver producing the rise in temperature was human activities. Pérez-Lombard et al. [11] present a review of building energy consumption, concluding that $20 \%-40 \%$ of total energy use in developed countries was due to the energy consumption of buildings, making energy efficiency strategies a priority for energy policies, building regulations and certifications schemes.

The term "carbon footprint" has many interpretations, ranging from direct carbon dioxide emissions to full life-cycle GHG emissions and there is no consensus on how to measure or quantify a carbon footprint [9, 12]. Wiedmann and Minx [12] reviewed a number of carbon footprint definitions and concluded that carbon footprint is a "measure of the exclusive total amount of carbon dioxide emissions that is directly and indirectly caused by an activity or is accumulated over the life stages of a product. Wiedmann and Minx [12] emphasised that the activity include the activities of individuals, populations, governments, companies, organisations, processes, industry sectors etc., while the products include goods and services. Other authors have defined carbon footprint as "a measure of the amount of carbon dioxide emitted through the combustion of fossil fuels", "a measure of the impact human activities have on the environment in terms of the amount of GHG produced, measured in tonnes of carbon dioxide" or "technique for identifying and measuring the individual GHG emissions from each activity within a supply chain process step and the framework for attributing these to each output product” [12]. Hence carbon footprint is used as a generic term for carbon dioxide or GHG emissions.

Increasingly, tackling carbon footprints as a way of abating climate change, is becoming significant in all aspects of business activities due to the impact of legislation and regulations [3, 13-15], emphasis on CSR (corporate social responsibility) [4, 16], and Customer and Stakeholder demands and values [8, 16]. The UK government and the European Union are constantly introducing new climate change policies and regulations that encourage businesses to achieve improved energy efficiency, reduce their carbon footprints and produce environmental impact reports [17]. In addition, the narrative reporting requirements under the 2006 Companies Act encourages UK firms to 
discuss non-financial issues like environmental matters, employees and social issues. Chen and Bouvain [18] investigated CSR reporting in the USA, UK, Australia, and Germany and concluded that emphasis on environmental issues diverged considerably depending on institutional arrangements. Other studies advocated issues covered in CSR reports are varied, country and industry-specific” [5, 19, 20]. For example, KPMG [5] highlighted the fact that "carbon footprint reporting is not as common as might be expected” but a significant number of UK businesses did report on their carbon footprints compared with others. The KPMG report [5] concluded that within the carbon footprint reports reviewed, much of the emphasis was on individual operations and not supply chains. A growing concern is that within carbon footprint reports, companies are measuring too many issues of which many do not converge. Awareness of these key issues would enable further understanding of carbon footprint reporting and the adoption of carbon footprint reporting standards.

\section{Determining which Elements of Carbon Footprint to Report}

Regardless of the lack of adequate reporting on issues relating to carbon footprints, a number of environmental responsibility reporting frameworks and standards like the GRI (Global Reporting Initiative) and the UN Global Compact are emerging [18]. Chen and Bouvain [18] suggest that the use of these standards and frameworks for reporting only affected certain environmental and workers issues. However, the key issues concerning carbon footprint management have not been yet highlighted, although carbon footprints (carbon emissions) are now becoming a very significant metric for organizational management and sustainability goals. A question of practical significance is which key issues are critical for reporting?

From an environmental perspective, the Global Reporting Initiative [21, 22] suggests the following as some of the key issues that should be included in company reports:

- Energy consumed and saved;

- Water conservation, used and reused;

- GHG emissions - initiatives to reduce $\mathrm{CO}_{2}$ and other harmful GHG emissions;

- Waste by type and disposal method, materials used including percentage recycled;

- Transportation.

The purpose of this framework is identifying and emphasizing issues that offer significant carbon reduction as well as need further action to achieve carbon reduction. Most importantly, there is an underlying assumption that there is a set of values that can be applied to manage carbon emissions and sustainability in general. However, from a practical perspective and within a national set of carbon emission targets, often, individual institutions and businesses decide how to reduce, review and report progress on their own carbon footprints. This paper seeks to identify the key carbon footprint issues from the perspective of facilities managers as one sector of great impact is the built environment.

\subsection{Energy Consumption and GHG Emissions}

The rise in energy consumption and $\mathrm{CO}_{2}$ emissions has made energy efficiency management strategies a primary goal for many organizations and institutions. For instance, Nousiainen and Junnila [8] found in their study of environmental objectives and demands of end users organization that energy efficiency, waste management and reduction of greenhouse emissions are the important for end-users of buildings. A number of studies suggested that building energy use is the largest energy end use both in the residential and non-residential sector, comprising lighting, heating, ventilation and air conditioning [2, 11, 23, 24]. For instance, for building energy consumption, the HVAC (heating, ventilation and air-conditioning) averages for $48 \%$, lighting averages $35 \%$ and other office and electronic equipment average $17 \%$ [23]. This suggests 
that building energy consumption is a critical activity that impacts on $\mathrm{CO}_{2}$ emissions and therefore a key area for reporting carbon reduction management.

\subsection{Waste Disposal and Recycling}

Managed waste disposal and recycling can help reduce environmental impacts and carbon emissions. Disposal of products that can be reused, recycled or repaired is a waste of the considerable quantities of energy and resources used in producing or processing them [25]. Similarly excessive packaging uses additional energy to produce, transport and disposed of. Hence although waste disposal and recycling cannot reduce carbon emissions directly, it has an impact on the environment from a sustainability perspective. Recycling uses less energy and produces less pollution than it would take to make a new product. For example, only $8.3 \%$ of the energy used in producing aluminium cans from raw materials is required to recycle and produce new cans from used cans. Similarly $315 \mathrm{~kg}$ of $\mathrm{CO}_{2}$ is saved per ton of glass bottles recycled after taking into account its transportation and processing [26]. The management of waste disposal and recycling is influenced by the sectors individual businesses' waste management strategies [27, 28], hence a potential issue for carbon foot reporting.

\subsection{Water Consumption}

Similar to waste disposal and recycling discussed previously, water consumption does not directly impact on carbon emissions. However, substantial amounts of energy are required to make it sterile for commercial and domestic use [29]. Another issue is the harvesting and recycling of grey water, which makes up $50 \%$ to $80 \%$ of wastewater all over the world, to treat lawns and gardens. Hence a potential issue for carbon footprint reporting.

\subsection{Transport}

Road transport, shipping and air flights are significant contributors to energy demands and GHG emissions with large parts of the emissions emanating from fossil fuels used [30, 31]. Businesses and individuals regularly use of some forms of transportation like commuting to work, business travels and public transport.

\section{Research Design and Data Collection}

The study of carbon footprint issues addressed in environmental impact reports formed part of a larger annual survey investigating how facilities professionals were engaging with sustainability issues. The research aims to establish the level of understanding and opinion towards economic, social and environmental sustainability issues among facilities management professionals.

\subsection{Research Design}

An online self-administered questionnaire survey was considered the most appropriate method of examining the level of understanding, and opinions toward carbon footprint issues reported in environmental impact reports, among facilities management practitioners. Questionnaire surveys have been used in investigating perceptions and opinions of respondents in several industries in the UK [5, 7]. Elmualim et al. [7] used it to investigate the barriers and commitment of facilities management profession to the sustainability agenda.

As with previous three annual surveys [7], prior to administering the questionnaire online, news items about the survey were published in FM World magazine and on the BIFM (British Institute of Facilities Management) website to raise awareness about the survey among the BIFM members. The questionnaire was then piloted among a small number of practicing facilities managers. The results of the pilot study was discussed by a focus group organized by the project's steering committee, comprising twelve practicing facilities managers and one academic. The questionnaire was accepted as the main data collecting instrument. In order to have a broad spectrum of 
facilities management professionals participating in the survey, accessibility to the online survey instrument was open to all BIFM members and non-members for a period of one month in May 2010. No names or identifying information were requested on the questionnaires, and all respondents were assured of absolute confidentiality.

\subsection{Data Collection}

The questionnaire instrument involved 20 closed questions and five open questions. However, to identify the key issues addressed by carbon footprint management strategies, opinions and perceptions were sought by asking respondents to simply select key carbon footprint issues managed and reported in their carbon footprint reports. Informed by literature reviews, interviews and case studies, the ten key carbon footprint issues considered relevant to managing carbon footprints were waste disposal and water consumption, building energy consumption, commuter travel, supply chain emissions, commercial travel, Business travels - company cars and business travels - public transport, business air travels and non-building energy consumption.

To identify the key issues of managing and reporting carbon footprints activities, the data captured was entered into a Microsoft Excel database and analyzed using descriptive statistics. A total of 268 respondents completed the survey online compared to 251 respondents in 2007, 168 in 2008 and 222 in 2009.

\subsection{Limitations}

As with all self-administered questionnaire surveys there are a number of limitations associated with the online questionnaire surveys like inability to prompt for explanations and the uncertainty of the profile of respondents. For example, there was no support for respondents who had difficulty in understanding some specific questions. Similarly, respondents could not be prompted to explain their views or reasoning behind certain responses. Prompting respondents will have enhanced the quality of the information provided. To overcome this shortcoming a series of case studies were conducted to complement the survey findings. The online platform does not allow for verification of respondents' profile. However, it is hoped that majority of respondents are FM professionals with a genuine interest in sustainability issues.

\section{Survey Results}

\subsection{Demographic Characteristics of Respondents}

Among the respondents, more that $90 \%$ were members of the BIFM with over $63 \%$ having full membership, an indication of them having at least five years of management experience and three years of FM experience. More than $50 \%$ of the respondents worked in in-house facilities management departments, while $25 \%$ worked in organizations outsourced as FM service providers and 9\% in independent FM consultants. Clearly majority of the respondents provided FM services in one form or another, hence were well-informed about the opinions, needs and wants of FM professionals engaging with the sustainability practices and strategies.

\subsection{Perceptions of Carbon Footprint Management and Reporting}

Of the 268 respondents who completed the survey, a total of 178 (66\%) respondents answered the question on carbon footprint management. Of these, $90 \%$ selected building energy consumption as the key issue addressed by their carbon footprint management strategies. A further $81 \%$ and $67 \%$ of respondents selected waste disposal and water consumption as important issues addressed by carbon foot management respectively. Other issues selected by the respondents were business travel - company cars (53\%) and business travel - air travel (43\%). The least covered aspects include supply chain emissions (21\%); commercial transport (21\%); and commuter travel (20\%). Table 1 shows the ranking of the issues addressed by carbon footprint management ranked 
according to the issues most selected by the respondents, building energy consumption, waste disposal, and water consumption are the main carbon footprint issues managed by the respondents. The issues least selected were commuter travel, supply chain emissions, commercial transport and non-building energy consumption. Table 2 shows a comparison of the issues over a four year period.

Table 2 shows that over the last four years, building energy consumption, waste disposal, water consumption, business travel - company cars and business travel - air travel remain as the key issues on which data is collected, measured and reported in environmental reports as part of their sustainability activities. Significantly, the percentage of respondents who selected business travel - company cars and business travel — public transport increased by $14 \%$ and $11 \%$ respectively in 2010. However, business travel - company cars is still ranked fourth while Business travel — public transport is ranked sixth.
Table 1 Ranking of issues addressed by carbon footprint management strategies.

\begin{tabular}{lll}
\hline Carbon footprint issues & $\begin{array}{l}\text { Number } \\
\text { respondents (\%) }\end{array}$ & $\begin{array}{c}\text { of } \\
\text { Ranking }\end{array}$ \\
\hline Building energy consumption & $160(89.9 \%)$ & 1 \\
Waste disposal & $144(80.9 \%)$ & 2 \\
Water consumption & $119(66.9 \%)$ & 3 \\
Business travel—company cars & $94(52.8 \%)$ & 4 \\
Business travel一air travel & $77(43.3 \%)$ & 5 \\
Business travel—public transport & $66(37.1 \%)$ & 6 \\
Non-building energy consumption & $54(30.3 \%)$ & 7 \\
Commercial transport & $37(20.8 \%)$ & 8 \\
Supply chain emissions & $37(20.8 \%)$ & 9 \\
Commuter travel & $35(19.7 \%)$ & 10 \\
\hline
\end{tabular}

The percentage of respondents who identified commuter travel, supply chain emissions and commercial transport has generally declined compared to a 2007 baseline (Table 2). Non-building energy consumption (i.e., street and outdoor lighting, water and sewage treatment, and other miscellaneous end-uses) has also declined from $40.0 \%$ in 2008 to $30.3 \%$ in 2010.

Table 2 A comparison of issues addressed by carbon footprint management strategies between 2007 and 2010 [32-34].

\begin{tabular}{lcccc}
\hline & \multicolumn{4}{c}{$\%$ of respondents (ranking) } \\
\cline { 2 - 5 } Issues & 2007 & 2008 & 2009 & 2010 \\
\hline Building energy consumption & $85.0 \%(1)$ & $88.0 \%(1)$ & $84.6 \%(1)$ & $89.9 \%(1)$ \\
Waste disposal & $75.0 \%(2)$ & $80.0 \%(2)$ & $73.1 \%(2)$ & $80.9 \%(2)$ \\
Water consumption & $72.0 \%(3)$ & $68.0 \%(3)$ & $66.9 \%(3)$ & $66.9 \%(3)$ \\
Business travel—company cars & $69.0 \%(4)$ & $58.0 \%(4)$ & $38.5 \%(4)$ & $52.8 \%(4)$ \\
Business travel—air travel & $53.0 \%(5)$ & $48.0 \%(5)$ & $38.5 \%(4)$ & $43.3 \%(5)$ \\
Business travel—public transport & $45.0 \%(6)$ & $32.0 \%(8)$ & $27.7 \%(7)$ & $37.1 \%(6)$ \\
Non-building energy consumption & $0.0 \%(10)$ & $40.0 \%(6)$ & $29.2 \%(6)$ & $30.3 \%(7)$ \\
Other supply chain emissions & $41.0 \%(7)$ & $33.0 \%(7)$ & $15.4 \%(10)$ & $20.8 \%(8)$ \\
Commercial transport & $37.0 \%(8)$ & $17.0 \%(9)$ & $16.9 \%(9)$ & $20.8 \%(8)$ \\
Commuter travel & $31.0 \%(9)$ & $15.0 \%(10)$ & $23.1 \%(8)$ & $19.7 \%(10)$ \\
\hline
\end{tabular}

\section{Discussions}

As $66 \%$ of respondents answered questions relating to carbon footprint management and reporting, this indicates that every two out three respondents was aware or involved in carbon footprint management. Nearly $90 \%$ of these respondents indicated that building energy consumption was an environmental quality concern in terms of managing carbon footprints.
This also implies that majority of the respondents' perceptions are largely directed towards both the environmental impact of building energy use, utility use and non-building energy use. The results also correlated with previous study reports (see Table 2). Although this finding supports previous reports, it is in sharp contrast to the idea that industry and transportation are the main energy consumption or associated carbon emission sector [31]. A reason might 
be that the built environment (commercial and residential) consumes as much as $45 \%$ of generated energy to produce power and heat [11, 35] and associated GHG emissions. The results indicate that among the respondents, addressing the impact of building energy use on the environment is the most critical element in managing carbon footprints. Often this involves addressing strategies, collecting and measuring data on building energy use like heating, cooling, ventilation and lighting. The results also support the fact that energy efficiency is a cost-effective carbon footprint management strategy.

Waste disposal is ranked as the second critical element addressed with respect to carbon footprints reports (Table 2). This result indicates that in order to reduce carbon footprints, respondents are adopting and reporting on more environmentally responsible waste disposal like reducing, recycling, and reusing strategies for waste materials. Clearly, reuse, recycle, and reduce (possibly repair and recover) strategy is one way that respondents reduced carbon footprints. In addition, repair and recover strategies. However a reason may be the liability and cost implications of regulations put in place by the government regulations and directives. Also by managing waste disposals, less waste is sent to landfills reducing carbon emissions from transporting the solid waste materials.

Water consumption was highly ranked as a critical issue for carbon footprint management as it indirectly influences carbon emissions. This finding implies water consumption is now a critical issue as it recognized a limited natural resource. Harvesting and recycling of grey water has a great potential to conserve water and reduce sewage treatment plants and hence energy.

Clearly the results indicate that less than half of the respondents selected business travels as a top priority in managing their carbon footprint, even though transportation is major contributor to GHG emissions [30, 31]. This might be due to the fact that transportation can be a very emotive issue as everyone uses some form of transport daily and that business without transportation cannot be encouraged. This view is further reflected in the least number of respondents considering commuting as a very critical issue for managing carbon footprint. This may be due to the fact that, often, businesses do not reflect on how far employees travel from and how much it contributes to carbon emissions. Clearly encouraging employees to find the lowest impact commuting options like home-working and using public transport could go a long way to reduce carbon footprints. Furthermore, if business travels are pooled together, carbon footprint could be reduced when travelling in groups.

Interestingly, non-building energy consumption such as street and outdoor lighting and water and sewage treatment systems were highly rated than commuting and supply chain emissions (Table 2). A reason might be that street lighting and sewage treatment are often the responsibility of government or local government or facilities landlords. The results also indicate that not much is considered of the supply chain GHG emissions as supply chains can be very complicated especially where several products, services, are used in producing the organizations final product.

\section{Conclusions}

In the UK, concern for the social and environmental impact of business activities, encouraged by tightening legislative requirements and reputational risks, has led to businesses reporting on non-financial issues such as carbon footprint in their annual reports. However, a lack of consensus on key issues relating to the management and reporting of carbon footprint means a wide range of activities and issues are included in the reports. Hence, the questionnaire survey was conducted, among facilities managers, to identify critical carbon footprint issues or activities that were managed and reported upon within businesses.

The study findings indicated that building energy consumption, selected by majority of the respondents, 
is the most popular carbon footprint issue addressed in environmental impact reports. Building energy consumption will continue to dominate the management of carbon footprints due to the significance of buildings and associated energy needs to business operations. Furthermore, the variety of energy consumption activities that occur in buildings and facilities means it offers business opportunities to manage their carbon footprints. Majority of the respondents identified management of waste disposal and recycling as a critical issue addressed within the reports. Clearly, reusing, recycling, and reducing waste material within businesses is viewed as one way of reduced carbon footprints in directly. The third most popular issue, selected by the respondents, is water consumption. Other issues identified by the respondents were business travels and non-building energy consumption. The least popular issue identified by the respondents is commuter travels.

In general, the critical issues identified in this study reveal how facilities managers are engaging with reducing carbon emissions. The critical carbon footprint issues identified can help lead to improvement or development of good sustainable practices for carbon footprints management and reporting.

\section{Acknowledgment}

The authors would like to acknowledge the contribution and support of the Engineering and Physical Sciences Research Council (EPSRC), the British Institute of Facilities Management (BIFM) and Sustainability Special Interest Group members.

\section{References}

[1] CROWN, Climate Change Act 2008, available onlie at: http://www.opsi.gov.uk/acts/acts2008/pdf/ukpga2008002 7en.pdf.

[2] D. Prasad and M. Hall, Construction challenge: Sustainability in developing countries, in: Leading Edge Series, RICS, London, 2004.
[3] N. Wang, Y. C. Chang and V. Dauber, Carbon print studies for the energy conservation regulations of the UK and China, Energy and Buildings 42 (5) (2010) 695-698.

[4] D. Walker, M. Pitt and U. J. Thakur, Environmental management systems: Information management and corporate responsibility, Journal of Facilities Management 5 (1) (2007) 49-61.

[5] KPMG, KPMG International Survey of Corporate Responsibility Reporting, Amstelveen, 2008.

[6] S. Shah, Sustainable Practice for the Facilities Manager, Blackwell Publishing, Oxford, 2007.

[7] A. Elmualim, D. Shockley, R Valle, G. Ludlow and S. Shah, Barriers and commitment of facilities management profession to the sustainability agenda, Building and Environment 45 (1) (2010) 58-64.

[8] M. Nousiainen, S. Junnila, End-user requirements for green facility management, Journal of Facilities Management 6 (4) (2008) 266-278.

[9] G. P. Peters, Carbon footprints and embodied carbon at multiple scales, Current Opinion in Environmental Sustainability 2 (4) (2010) 245-250.

[10] R. K. Pachauri and A. Reisinger, Climate Change Synthesis Report, Contribution of Working Groups I, II and III to the Fourth Assessment Report of the Intergovernmental Panel on Climate Change, IPCC, Geneva, Switzerland, 2007, p. 104.

[11] L. Pérez-Lombard, J. Ortiz and C. Pout, A review on buildings energy consumption information, Energy and Buildings 40 (3) (2008) 394-398.

[12] T. Wiedmann and J. Minx, A definition of "carbon footprint”, in: C. C. Pertsova (Ed.), Ecological Economics Research Trends, Nova Science Publishers: Hauppauge, NY, USA. 2008, pp. 1-11.

[13] D. Shiers, A. Lavers and M. Keeping, Indicators of the impact of environmental factors on UK construction law: Developments in the new millennium, Construction Management and Economics 25 (7) (2007) 821-829.

[14] J. I. Scrase, Curbing the growth in UK commercial energy consumption, Building Research \& Information: The International Journal of Research, Development and Demonstration 29 (1) (2001) 51-61.

[15] X. G. Casals, Analysis of building energy regulation and certification in Europe: Their role, limitations and differences, Energy and Buildings 38 (5) (2006) 381-392.

[16] M. Loosemore and F. Phua, Responsible Corporate Strategy in Construction and Engineering: Doing the Right Thing? Spon Press, Abingdon, UK, 2011.

[17] R. U. Ayres, H. Turton and T. Casten, Energy efficiency, sustainability and economic growth, Energy 32 (5) (2007) 634-648.

[18] S. Chen and P. Bouvain, Is corporate responsibility converging? A comparison of corporate responsibility 
reporting in the USA, UK, Australia, and Germany, Journal of Business Ethics 87 (2009) 299-317.

[19] A. Kolk, Environmental reporting by multinationals from the triad: Convergence or divergence?, Management International Review 45 (1) (2005) 145-166.

[20] KPMG, UNEP, Carrots and Sticks for Starters, Current Trends and Approaches in Voluntary and Mandatory Standards for Sustainability Reporting, KPMG/UNEP, Parktown and Paris, 2006.

[21] Global Reporting Initiative, A Snapshot of Sustainability Reporting in the Construction and Real Estate Sector, 2008.

[22] Global Reporting Initiative, Sustainability Reporting Guidelines, GRI, Boston, USA, 2002.

[23] G. N. Spyropoulos and C. A. Balaras, Energy consumption and the potential of energy savings in Hellenic office buildings used as bank branches - A case study, Energy and Buildings 43 (4) (2011) 770-778.

[24] B. Roisin, M. Bodart, A. Deneyer and P. D'Herdt, Lighting energy savings in offices using different control systems and their real consumption, Energy and Buildings 40 (4) (2008) 514-523.

[25] I. Baxter, A new age in waste management? Available online at: http://facilities-manager.co.uk/ index2.php?option=com_content\&do_pdf=1\&id=64.

[26] British Glass, Life Cycle Analysis of Glass Recycling (Summary), British Glass, Sheffield, UK, 2004.

[27] M. Pitt, Trends in shopping centre waste management, Facilities 23 (11/12) (2005) 522-533.
[28] M. Pitt and A. Smith, An assessment of waste management efficiency at BAA airports, Construction Management and Economic 21 (4) (2003) 421-431.

[29] S. Botto, V. Niccolucci, B. Rugani, V. Nicolardi, S. Bastianoni and C. Gaggi, Towards lower carbon footprint patterns of consumption: The case of drinking water in Italy, Environmental Science \& Policy 14 (4) (2011) 388-395.

[30] .S. FuglestvedT, K. P. ShinE, T. Berntsen, J. Cook, D. S. Lee, A. Stenke, R. B. SkeiE, G. J. M. Velder and S. I. A. Waitz, Transport impacts on atmosphere and climate: Metrics, Atmospheric Environment 44 (37) (2010) 4648-4677.

[31] J. Fuglestvedt, T. Berntsen, G. Myhre, K. Rypdal and R. B. Skeie, Climate forcing from the transport sectors, in: Proceedings of the National Academy of Sciences of the United States of America, Vol. 105, 2008, pp. 454-458.

[32] A. Elmualim, G. Ludlow, S. Shah and R. Valle, BIFM (British Institute of Facilities Management) Sustainability Survey Report, BIFM, Bishops Stortford, UK, 2009.

[33] M. Pastou, A. Elmualim, G. Ludlow, R. Valle and S. Shah, BIFM (British Institute of Facilities Management) Sustainability Survey Report, BIFM, Bishops Stortford, UK, 2008,

[34] D. Shockley, BIFM Sustainability Survey Report, BIFM, Bishops Stortford, 2007.

[35] B. Wood, The role of existing buildings in the sustainability agenda, Facilities 24 (1-2) (2005) 60-67. 